\title{
The potential of tree rings in Terra Australis
}

Chris Turney ${ }^{1}$, J. Palmer ${ }^{1}$, K. Allen², P. Baker ${ }^{2}$ and P. Grierson ${ }^{3}$

\section{To overcome the relative dearth of paleoclimate records in Southern Hemisphere mid-latitudes, new methods are} being developed in Australasia to exploit the potential of tree rings across the region.

The Australasian region is potentially highly sensitive to climate change, including abrupt transitions caused by the crossing of thresholds within different components of the climate system (Fig. 1). Accurate reconstructions of the past behavior of the climate system are needed to better understand the mechanisms, and to validate projections of future change at the junction between tropical and polar regions (PAGES 2k Consortium 2013). Tree-rings are critical in this regard.

Over the $20^{\text {th }}$ century, dendroclimatic research in the Northern Hemisphere has advanced in leaps and bounds. In the Southern Hemisphere the much smaller land mass and less amenable tree species have limited the development of long proxy climate records from trees. However, during the past five years, significant technical advances and discoveries have created an exciting set of opportunities for increasing the quality and understanding of tree-ring-based climate reconstructions in the Australasian region and, potentially, other tree-bearing regions of the world.

\section{Tree ring growth analysis}

Like most proxy-climate reconstructions, those from tree rings are developed from statistical models relating observed climate data to measured tree-specific features such as ring widths. While these models are typically based on the correlation between two variables, causation is inferred from detailed understanding of the physiological mechanisms that drive tree growth and tree-ring formation. Recent technological and analytical advances have created the potential to monitor radial growth and wood cell formation at sub-hourly resolution over multiple years (Drew and Downes 2009). For the first time, this enables an assessment of the role of weather and climate in tree-ring formation for long-lived trees of global paleoclimatic importance from Australia and New Zealand (Drew et al. 2013; Wunder et al. 2013).

\section{Wood properties beyond ring-width}

Particular interest has been focused on the recent development of tree-ring chronologies based on wood microfibril angle (MFA; angle of cellulose microfibrils in the cell wall relative to the long axis of the cell) and tracheid radial diameter (TRD). Both exhibit a strong temperature sensitivity during the austral summer, i.e. November to April (Drew et al. 2013), extending across much of temperate south-eastern Australia (Allen et al. 2013). This development is particularly important as the wood-property chronologies were developed from samples that exhibited no sign of a climate signal in ring width, although the wood-properties based results appear stronger and more temporally stable than the widely cited Mt Read summer temperature reconstruction from Tasmanian Huon pine (Cook et al. 2000). As these authors point out, the results demonstrate the potential of wood property chronologies to open up vast areas for dendroclimatic research in data-sparse regions of Australasia, and beyond,

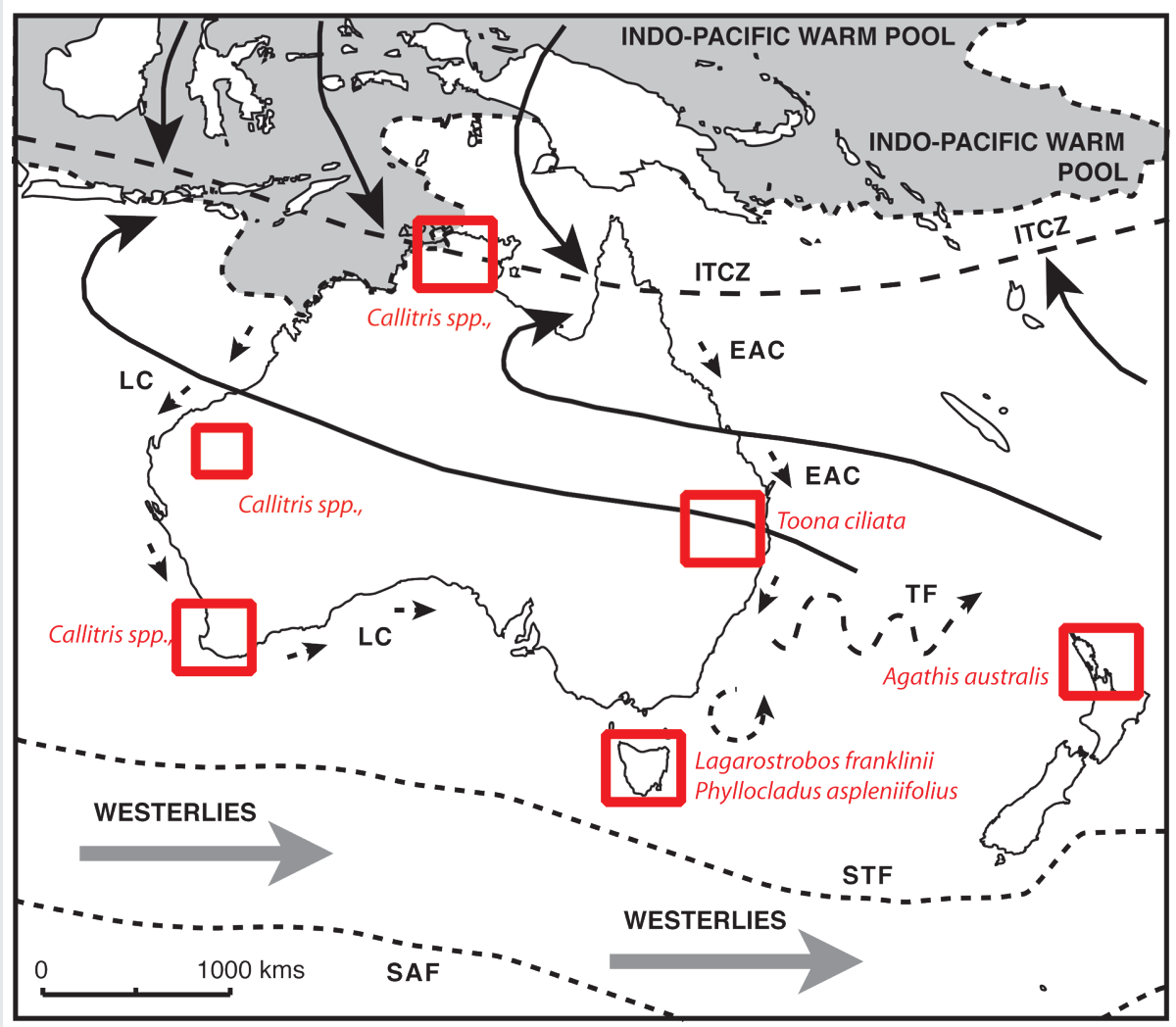

Figure 1: Location of Australasian tree-ring sites discussed in the text with major climatic and oceanographic boundaries shown. ITCZ denotes Intertropical Convergence Zone, LC the Leeuwin Current, EAC the East Australian Current, TF the Tasman Front, STF the Sub Tropical Front, and SAF the Subantarctic Front. where standard ring-width chronologies have provided little dendroclimatic value.

The relative paucity of climate-sensitive, multi-millennial tree-ring chronologies in the Southern Hemisphere makes it particularly important to examine whether the existing chronologies exhibit signs of anomalous growth reduction (the so-called "divergence prob$\left(\mathrm{lem}^{\prime \prime}\right)$, as identified in the Northern Hemisphere (D'Arrigo et al. 2008). A program is currently underway to update long, climate-sensitive chronologies in the Southern Hemisphere as many lack ring-width data from the last 20 years or more. The investigation includes an assessment of several factors: the impact of various methods of standardization; the impact of

\section{Investigating divergence}




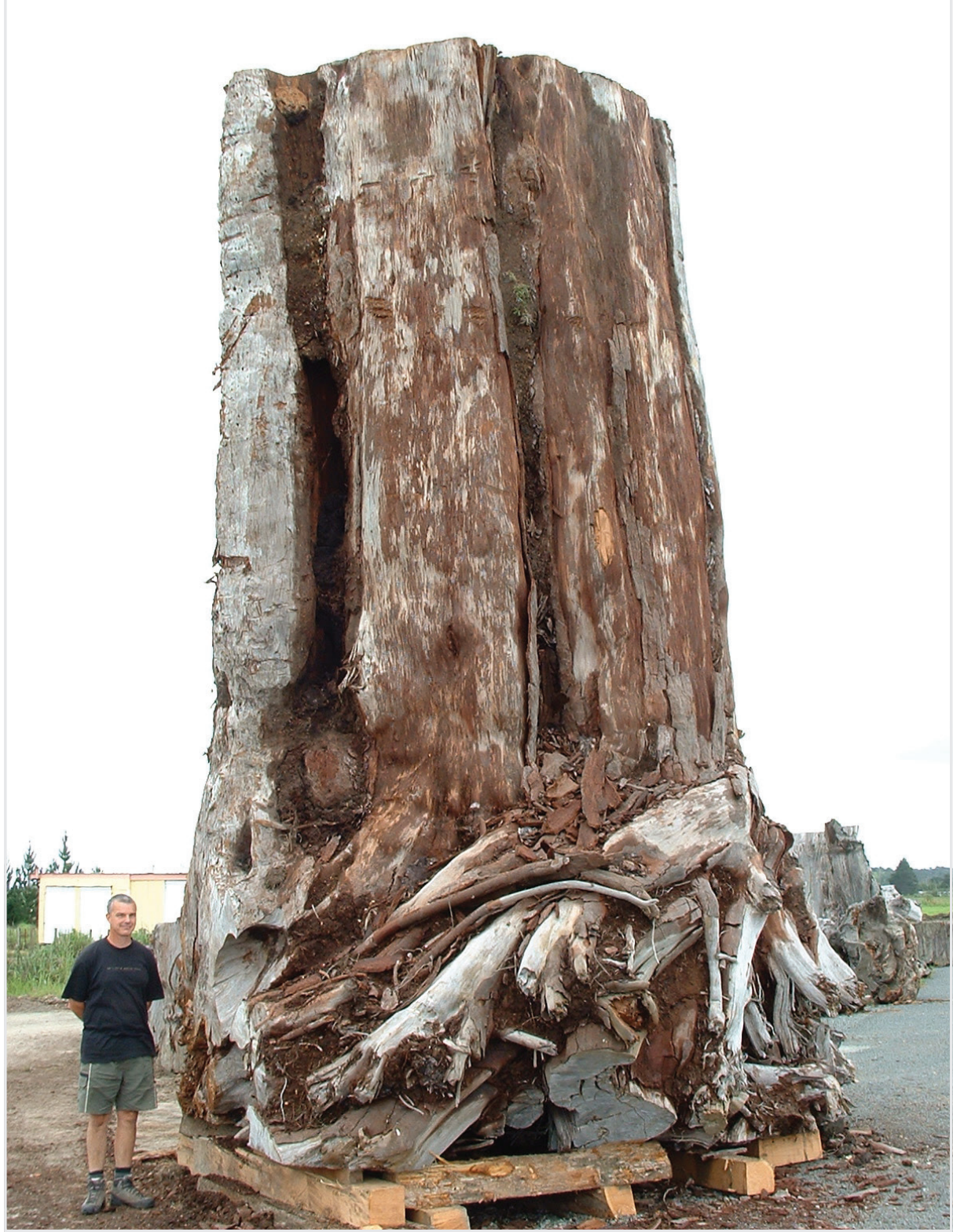

Figure 2: Ancient kauri tree (Agathis australis) prior to commercial processing in Northland, New Zealand (Jonathan Palmer pictured for scale).

signal-free processing (Melvin and Briffa 2008); and whether or not relationships between climate and wood-properties (e.g. density, TRD, MFA) may be more temporally stable than for ring-width. In addition, high-resolution data will provide a better empirical understanding of the climate response of trees at key sites (Fig. 1) and of the mechanisms underpinning any observed patterns of divergence between tree-ring properties and climate.

\section{Filling in knowledge gaps}

The eucalypts and acacias that dominate the Australian landscape generally lack discernible annual growth rings and, until recently, have not been considered suitable for climatic reconstructions (Brookhouse 2006). However, annually-resolved tree-ring chronologies have been recently developed from selected high-elevation species of these genera. The early despondent reports of the poor potential for tree-ring chronologies across much of Australia is being overcome by the development of a range of new chronologies that are based on measurements of ring width coupled with $\delta^{13} \mathrm{C}$ of cyclones that drive rainfall patterns across much of northern Australia (Cullen and Grierson 2007). Such an approach is needed to provide the spatial infilling crucial for exploring teleconnections and their temporal stability, particularly regarding the influence of climate modes, such as the El Niño-Southern Oscillation, the Southern Annular Mode and the Indian Ocean Dipole, on the Australasian region (e.g. Neukom and Gergis 2010).

Reconstructing changes in the carbon cycle Despite considerable effort, the reliable treering dated section of the most recent internationally-accepted calibration curve (IntCal13; Reimer et al. 2013) based on North American and European trees extends back only to 12.59 cal ka BP (Schaub et al. 2008). An exciting Southern Hemisphere possibility for radiocarbon calibration exists in the form of subfossil kauri trees buried in bogs scattered over a 300 $\mathrm{km}$ stretch of northern New Zealand (Palmer et al. 2006). We know of nowhere else in the world with such a rich resource of subfossil wood that is capable of capturing the complete temporal range of radiocarbon. The time span preserved within these bogs covers more than $130 \mathrm{ka}$. These trees are of vast proportions and almost perfectly preserved (Fig. 2); individual trees can measure up to $4 \mathrm{~m}$ across and live for up to 2000 years. Within this precious archive is an annual record of past climate but, equally importantly, of changing atmospheric radiocarbon levels. The kauri trees have considerable potential to assist in the development of a Southern Hemisphere component of a unified global calibration curve. In addition, the tree-ring sequences can be superposed on other radiocarbon records to constrain carbon cycling in marine and atmospheric reservoirs at times of abrupt change (Turney et al. 2010). Most recently, the detailed analysis of kauri trees has been used to identify errors in Northern Hemisphere radiocarbon datasets (Hogg et al. 2013), providing a more accurate calibration for the transition to the Holocene, and potentially for the last glacial period.

\section{AFFILIATIONS}

${ }^{1}$ Climate Change Research Centre, University of New South Wales, Kensington, Australia

${ }^{2}$ Melbourne School of Land and Environment, University of Melbourne, Richmond, Australia

${ }^{3}$ School of Plant Biology, The University of Western Australia, Crawley, Australia

\section{CONTACT}

Chris Turney: c.turney@unsw.edu.au

\section{REFERENCES}

Allen Ket al. (2012) Dendrochronologia 30: 167-177 Baker P et al. (2008) Aust J Bot 56(4): 311-320

Cullen LE, Grierson PF (2009) Clim Dyn 33: 433-444

PAGES 2k Consortium (2013) Nat Geosci 6(5): 339-346 